\title{
A Review of Properties and Functions of Narrowband Internet of Things and its Security Requirements
}

\author{
Zana Azeez Kakarash ${ }^{1,2}$, Farhad Mardukhi \\ ${ }^{1}$ Department of Information Technology, University of Human Development, Sulaymaniyah, Iraq, ${ }^{2}$ Department of \\ Computer Engineering and Information Technology, Faculty of Engineering, Razi University, Kermanshah, Iran
}

\section{A B S T R A C T}

Internet of Things (loT) is a new web sample based on the fact that there are many things and entities other than humans that can connect to the Internet. This fact means that machines or things can automatically be interconnected without the need for interacting with humans and thus become the most important entities that create Internet data. In this article, we first examine the challenges of loT. Then, we introduce features of NB-loT through browsing current international studies on Narrowband loT (NB-IoT) technology, in which we focus on basic theories and key technologies, such as the connection number analysis theory, the theory of delay analysis, the coating increase mechanism, low energy consumption technology, and the connection of the relationship between signaling and data. Then, we compare some functions of NB-loT and other wireless telecommunication technologies in terms of latency, security, availability, and data transfer speed, energy consumption, spectral efficiency, and coverage area. Finally, we review and summarize NB-IoT security requirements that should be solved immediately. These topics are provided to overview NB-loT which can offer a complete familiarity with this area.

Index Terms: Internet of Things, Narrow Band, Internet of Things, Narrowband Internet of Things

\section{INTRODUCTION}

Internet of Things (IoT) is a long-term stream that we are currently at its earliest stage. We can consider three primary phases to achieve the first phase of IoT. In the first phase, things can be identified for us and others and gradually assign a specific address on the network for themselves. In this phase, each object keeps certain information in it, but these are people who need to take out this information using tools like their smartphones [1], [2], [3]. In the second

\begin{tabular}{|l|l|}
\hline \multicolumn{2}{|c|}{ Access this article online } \\
\hline DOI:10.21928/uhdjst.v4n1y2020.pp71-80 & $\begin{array}{l}\text { E-ISSN: 2521-4217 } \\
\text { P-ISSN: 2521-4209 }\end{array}$ \\
\hline
\end{tabular}

Copyright $\odot 2020$ Kakarash and Mardukhi. This is an open access article distributed under the Creative Commons Attribution Non-Commercial No Derivatives License 4.0 (CC BY-NC-ND 4.0) phase, each device has the ability to send information to the user at a specified time. After completing the relationship between objects and humans, it is time to relate things to each other. In the third phase, objects are associated with each other without human interference. Completing these three phases will finish the first phase of IoT evolution [4], [5].

At the end of the first phase, there is a world of ideas in front of developers. The problem is that each device has some information that is available on the network by other objects and its owner and developers can use their own creativity to make better use of this information; Telecommunication networks communicate with each other based on technologies, spectra, and different frequency band. This technology in recent years has been more widely considered with the advent of IoT technology/Internet of

\section{Corresponding author's e-mail: Zana Azeez Kakarash, Department of Information Technology, University of Human Development,} Sulaymaniyah, Iraq. E-mail: zana.azeez@uhd.edu.iq 
everything and the expansion of devices and communication networks with specific requirements [6], [7], [8].

Narrowband IoT (NB-IoT) is a low power radio network (low consumption) in a wide range (low power wide area network [LPWAN]), which is designed and developed to allow the connection of a large number of devices or services using cellular telecommunication band (cellular network) [9], [10].

The NB of Io'T focuses on network coverage in a closed space, less cost, and more battery life and has the ability to connect a large number of connected devices. The NB technology of IoT can be found in the spectrum in-band of the long-term evolution (LTE) network or the fourth generation in the frequency blocks of a fourth-generation operator or unused blocks (guard band) of a fourthgeneration operator. It can also be used alone for the deployment of a specific range. It is also appropriate for new combinations (re-farming of [global system for mobile (GSM) communication] spectrum) [11], [12].

The NB was first introduced and developed by Sig Fax (2009). This company faced the $3^{\text {rd }}$ generation partnership project (3GPP) institute, which defines cellular/mobile telecommunication standards with three challenges which have the ability to answer with a NB. The challenge is that there is a vibrant market for devices that:

1. Do not have a lot of abilities

2. They want to be very cheap

3. They have a low power consumption

4. Require high range (cover).

It can be said that the NB of IoT can exist in the following three conditions:

- Completely independent network

- In unused bands of $200 \mathrm{kHz}$, which previously used in GSM networks

- Second and third generations of mobile/communications

- At fourth-generation stations that can assign a block (frequency) to NB of the IoT or can be placed in (guard band) [13], [14], 15].

Finally, it can be said that the establishment of a NB of a network of IoT depends on the geographic conditions of the country and region as well as facilities and conditions of telecommunication and mobile operators of these countries. For example, in the United States, Verizon companies (Verizon and AT and T) can use LTE-M1 because both companies have invested in their fourth generation of the network; therefore, they probably do not want to create an independent network, and they want to have a network based on their current fourth-generation network [13], [14].

In front of areas of the world that have a wider GSM network than the fourth-generation network, it is rational to use an independent NB-IoT network. For example, T-Mobile operators in the United States and Sprint eventually have turned their attention toward the deployment of a NB network of IoT on the frequency spectrum of GSM network [13], [14], [15].

This paper recommends NB-IoT applicable models for application in many places to solve many problems (smart white goods, smart coordination's, smart power metering, and smart road lighting) and provides a comprehensive overview of the design changes brought in the NB-IoT standardization along with the detailed research advancements from the viewpoints of security requirements and the practical presentation of NB-IoT as far as successful throughput.

The rest of the paper is organized as follows. Section 2 describes some background concepts relevant to our review. Section 3 describes the challenges of IoT. Significant features of NB-IoT are described in Section 4. Section 5 presents NBIoT and different wireless communication technologies. In Section 7 describes basic requirements for NB-IoT security and in Section 8 discusses the conclusion.

\section{BACKGROUND}

\subsection{Brief Review of NB-loT}

NB-IoT is a guideline based low control wide zone (LPWA) innovation created to empower a wide scope of new IoT gadgets and administrations. NB-IoT essentially improves the power utilization of client gadgets, framework limit, and range effectiveness, particularly in profound inclusion. The battery life of beyond what 10 years can be upheld for a wide scope of utilization cases.

New physical layer flag and channels are intended to meet the requesting necessity of broadened inclusion - rustic and profound inside - and ultra-low gadget multifaceted nature. The introductory expense of the NB-IoT modules is required to be tantamount to GSM/General Packet Radio Services (GPRS). The basic innovation is anyway a lot more straightforward than the present GSM/GPRS and its expense is relied on to diminish quickly as interest increments.

By supporting all major equipment such as mobile equipment, chipset, and module producers, NB-Io'T can exist together 
with 2G (second-generation), 3G (third-generation), and 4G (forth-generation) versatile systems. It likewise profits by all the security and protection highlights of versatile systems, for example, support for client character classification, element confirmation, privacy, information respectability, and portable hardware distinguishing proof.

\subsection{Benefits and Constraints of NB-loT}

The main properties on NB-IoT technology, as defined in Rel-13 3GPP TR 45.820 [10], are given in Table 1.

We have to survey the basic points of interest and consequent restrictions in regards to the inalienable capacities of the NBIoT innovation to investigate the end-gadget activity and its incorporation with the IoT application [11], [12], [13], [14]. As planned ease of NB-IoT module presents no requirements and just brings benefits contrasting with other LPWA arrange arrangements, it would not be talked about further.

\subsubsection{Wide coverage and deep signal penetration}

This component gives a chance to the new application class of indoor and underground applications which incorporate information securing and control of gear situated in sewer vents, cellars, pipelines, and different conditions in which the existing correspondence foundation is inaccessible. Regardless of the improvement of sign entrance, the gadgets are relied upon to work on the lower limits of signature gathering. Hence, support for the vehicle of dependable information ought to be given as a piece of the availability arrangement.

\subsubsection{Low power consumption of NB-loT modules}

The chance of battery-controlled structure or potential vitality collecting for end-gadget arrangements, which brings about long life remain solitary activity, is considered as the quick advantage of the low force property. Since gadgets are required to work for quite a while, at that

\section{TABLE 1: NB-IoT main properties [42]}

\begin{tabular}{ll}
\hline Range & $<35 \mathrm{~km}$ \\
Battery life & $>10$ years \\
Frequency bands & LTE bands \\
Bandwidth & $200 \mathrm{kHz}$ or shared \\
Modulation & DL: OFDMA with $15 \mathrm{kHz}$ subcarrier spacing \\
& UL: Single tone transmissions -3.75 and \\
& $15 \mathrm{kHz}$, multi-tone SC-FDMA with $15 \mathrm{kHz}$ \\
& subcarrier spacing \\
Max throughput & $<56 \mathrm{kbps}$ UL, <26 kbps DL \\
Link budget & $164 \mathrm{~dB}$ \\
Capacity & $+50 \mathrm{k} \mathrm{loT}$ devices per sector
\end{tabular}

NB-IOT: Narrowband Internet of Things, OFDMA: Orthogonal frequency division multiple access, LTE: Long-term evolution, SC-FDMA: Single carrier frequency division multiple access point, reconfigurability is an ideal limit which features the requirement for sporadic, however, solid two-way correspondence. The two-way correspondence necessity is likewise seen by 3GPP in their rush hour gridlock model.

\subsubsection{Massive connectivity}

The inactive limit of NB-IoT supporting foundation is the gigantic availability coming about in up to $50 \mathrm{k}$ gadgets per cell, which relies on inclusion mode and traffic blend gadgets are utilizing. Since a huge number of gadgets are proposed to be coordinated into conveyed applications, unbounded remote help reaction time is normal, which is considered as one of the regular issues progressively enormous scope combinations. The correspondence measurements which are influenced incorporate the persistence of information correspondence, models for automatic repeat demand and stream control, and guaranteed unwavering quality (nature of administration) [38], [39], [40], [41].

\section{CHALLENGES OF THE IOT}

On IoT, we face a world in which makers supply their goods with their standards, and it is not clear, with the continuation of this variety, billions of devices that make up IoT, where will lead future of networks. We examine two challenges of IoT in this section. One of them is standard conflicts, and the other one is the security that puts the future of IoT in disorderly conditions [16], [17].

\subsection{Lack of Standard Unit}

The IoT of today has a different world. When the Internet standards were created, people controlled this standard that their true desire was to formulate global standards. Standards are equally accessible to everyone, but the Internet of today is in control of companies that each wants to use these standards to defeat competitors and benefit from them. Furthermore, the Internet is in the hands of governments that basically want to supervise everything. How do governments and companies in this situation want to agree on global standards? In the IoT, standard means everything.

Each device must announce to other devices what it wants to do. Without these standards, they cannot do any of these. Add this truth to challenge that equipments connected to IoT are very different and variant. Many companies and organizations try to set standards, and all see union, industrial Internet consortium, IPSO Union, and the open interconnect consortium are of the main institutions. In the IoT landscape, there are not spots at which all agree over a series of global standards [15], [16], [17], [18]. 


\subsection{Security}

A recent discovery of a bug called Bash or Shellshock uncovered a serious security issue on the IoT. The bug is a bunch of codes that allow hackers to run on UNIX and Linux operating systems, as shown in Fig. 1.

The bug is announced by the National Institute of Standards and Technology as a high-level security threat. The seriousness of the threat comes from the fact that hackers do not need to have prior knowledge of the attacked system before they add their code to the Bash bug. The bug does not affect the IoT only, but all devices connected to it are at risk of being attacked. Devices that are attacked by the bug remain to be uncatchable and vulnerable. This discovered threat suggests that there might be many unaddressed security issues, which is good news to hackers and Internet criminals and raise questions about the effectiveness and usability of IoT in the future.

Another aspect of IoT as contributing to security issues is its complexity, which makes it hard to identify security gaps. These gaps have been realized by researchers, as they have concluded that the connected world has many hidden risks that require intensive research to find suitable solutions [18], [19], [20]. Many devices through various channels can connect to IoT, and as yet no mechanism has been put forward to alert device users of security threats and the way they can prevent attacks from bash-like bugs.

\section{SIGNIFICANT FEATURES OF NB-IOT}

NB-IoT is another rapidly developing remote connectivity 3GPP cell innovation standard introduced in Release 13 that corresponds to Io'T's preconditions for the LPWAN. It is developing rapidly as the top-level driving innovation in LPWAN to enable a wide range of new IoT devices, including smart parking, utilities, wearables, and modern facilities.
Main features of NB-IoT are shown in Fig. 2 and briefly described below:

\subsection{Low Energy Consumption}

Using power saving mode (PSM) and infrequently developed receive (extended discontinuous receive [e-DRX]) Longer standby time can be observed in NB-IoT. In this context, PSM technology has been added lately to ReL12, in which terminal power-saving mode is still being recorded online, but it cannot achieve to saving energy by sending a signal to put the terminal in a deep sleep for a longer time [20], [21].

\subsection{Improved Coverage and Low Latency Sensitivity}

Given the reproduced information TR45.820, it very well may be affirmed that the intensity of the covering NB-IoT can find a good pace autonomous arrangement mode. Recreation try for both in-band organization and watchman band sending is finished. So as to advance the inclusion, systems, for example, remobilization (multiple times) and low recurrence tweak by NB IoT was endorsed. At present, NB-IoT support from quadrature amplitude modulation 16 is still under discussion. To lose blending $164 \mathrm{~dB}$, if a dependable information move gave, due to re-change of mass information, dormancy increments [13], [14], [15], [16], [17], [18].

\subsection{Transition Mode}

As it is shown in Table 2, NB-IoT development is based on LTE. Correction is mainly based on LTE-related technologies due to unique NB-IoT features. Radiofrequency bandwidth from NB-IoT physical layers is $200 \mathrm{kHz}$. At the bottom link, NB-IoT with quadrature phase-shift keying (QPSK) modem and orthogonal frequency-division multiple access technologies is compatible with a distance under carrier $15 \mathrm{kHz}$. In the uplink, binary phase-shift keying or QPSK modem and single-carrier frequency division multiple access innovations, including single sub-bearer and different

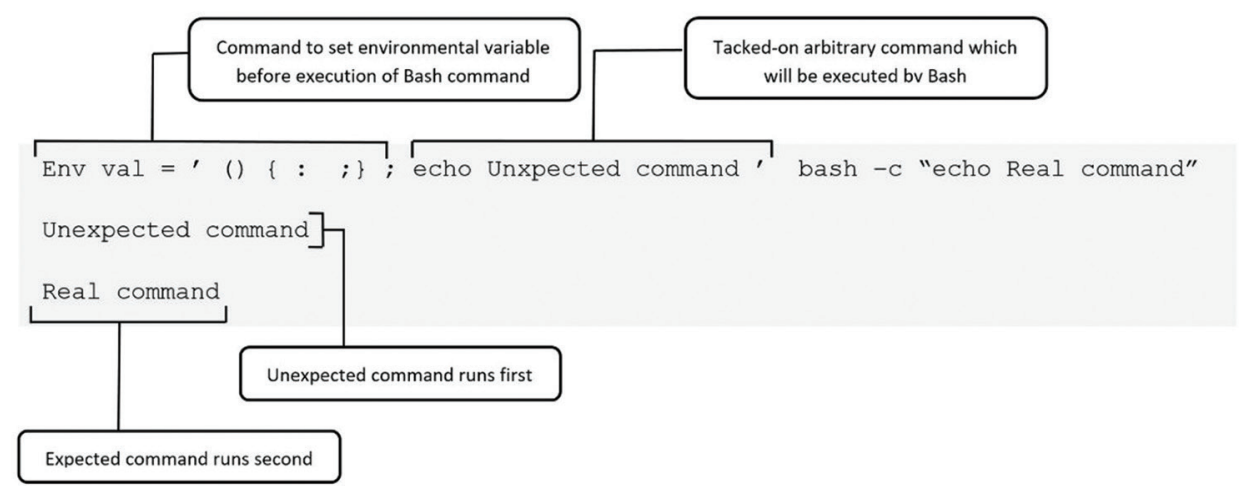

Fig. 1. How the function of code bash is vulnerable in the environment. 


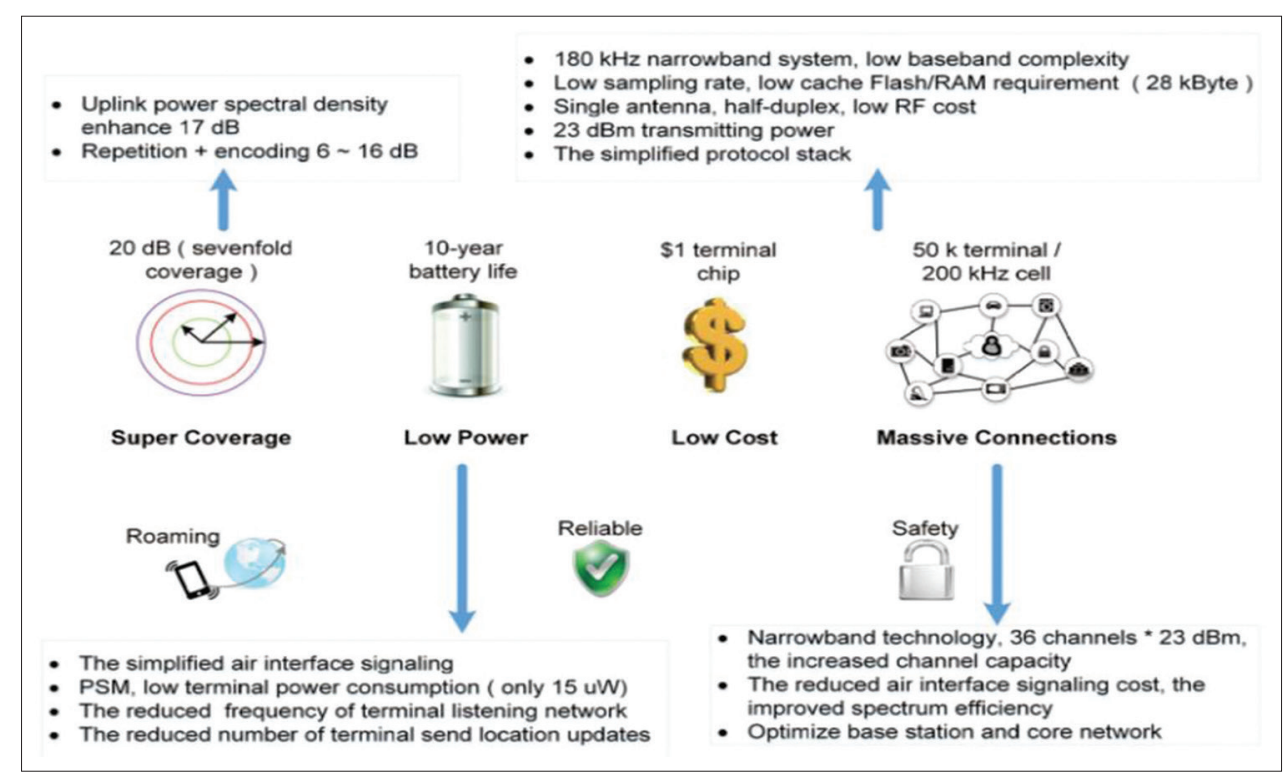

Fig. 2. Main features of Narrowband Internet of Things [42].

\section{TABLE 2: Main NB-IoT technical characteristics}

\begin{tabular}{|c|c|c|}
\hline \multirow{2}{*}{$\begin{array}{l}\text { Layer } \\
\text { Physical layer }\end{array}$} & \multicolumn{2}{|l|}{ Technical feature } \\
\hline & BPSK or $\mathrm{Q}$ & SK modulation \\
\hline & SC-FDMA & $\begin{array}{l}\text { Single carrier, the subcarrier interval is } 3.75 \mathrm{kHz} \text { and } 15 \mathrm{kHz} \\
\text { the transmission rate is } 160 \mathrm{kbit} / \mathrm{s}-200 \mathrm{kbit} / \mathrm{s} \\
\text { Multi-carrier, the subcarrier interval is } 15 \mathrm{kHz} \text {, the transmission rate is } 160 \mathrm{kbit} / \mathrm{s}-250 \mathrm{kbit} / \mathrm{s}\end{array}$ \\
\hline & $\begin{array}{l}\text { QPSK moc } \\
\text { OFDMA, th }\end{array}$ & $\begin{array}{l}\text { QPSK modulation } \\
\text { OFDMA, the subcarrier interval is } 15 \mathrm{kHz} \text {, the transmission rate is } 160 \mathrm{kbit} / \mathrm{s}-250 \mathrm{kbit} / \mathrm{s}\end{array}$ \\
\hline
\end{tabular}

BPSK: Binary phase-shift keying, NB-loT: Narrowband Internet of Things, OPSK: Quadrature phase shift keying, LTE: Long-term evolution, OFDMA: Orthogonal frequency division multiple access, SC-FDMA: Single carrier frequency division multiple access

subcarrier, are embraced. A solitary sub-bearer innovation with the sub-bearer separating of $3.75 \mathrm{kHz}$ and $15 \mathrm{kHz}$ is appropriate to IoT terminal with ultra-low rate and ultralow force utilization. The convention of NB-IoT high layer (the layer above physical layer) is figured through modification of a few LTE highlights, for example, multiassociation, low force utilization also, not many information. The center system of NB-IoT is associated through S1 interface [16], [17], [18], [19], [20], [21], [22].

\subsection{Spectrum Resources}

Io' is a core service that attracts a larger user group in the communication services market for the future. Hence, NB-IoT development supported by four major telecom operators in China, as shown in Table 3, which is the owner of FVHD NB-Io'T relevant spectrum source.

\subsection{Deployment Supported by NB-IoT}

According to RP-151621 regulations, NB-Io'T is currently only foreign demand draft transfer mode with a bandwidth of $182 \mathrm{kHz}$ and three types of deployment model shown in Fig. 3:

- Independent deployment (standalone mode), which utilizes a free recurrence band that has no cover with the LTE recurrence band

- Guard band deployment (protective band mode), which uses edge band frequency

- In-band deployment (in-band mode), which uses an LTE frequency band for deployment, and takes one physical resource block from LTE frequency band source for deployment [22], [23].

\subsection{Structure and Framework}

The bottom link in NB-IoT eNodeB supports from the wireless framework of E-UTRAN one frame structure 
TABLE 3: Spectrum classification for NB-IoT by telecom operators

\begin{tabular}{lccc}
\hline Operator & Uplink frequency band/MHz & Downlink frequency band/MHz & Bandwidth/MHz \\
\hline China unicorn & $909-915$ & $954-960$ & 6 \\
& $1745-1765$ & $1840-1860$ & 20 \\
China telecom & $825-840$ & $870-885$ & 15 \\
China mobile & $890-900$ & $934-944$ & 10 \\
& $1725-1735$ & $1820-1830$ & 10 \\
SARFT & 700 & 700 & Undistributed \\
\hline
\end{tabular}

NB-IOT: Narrowband Internet of Things

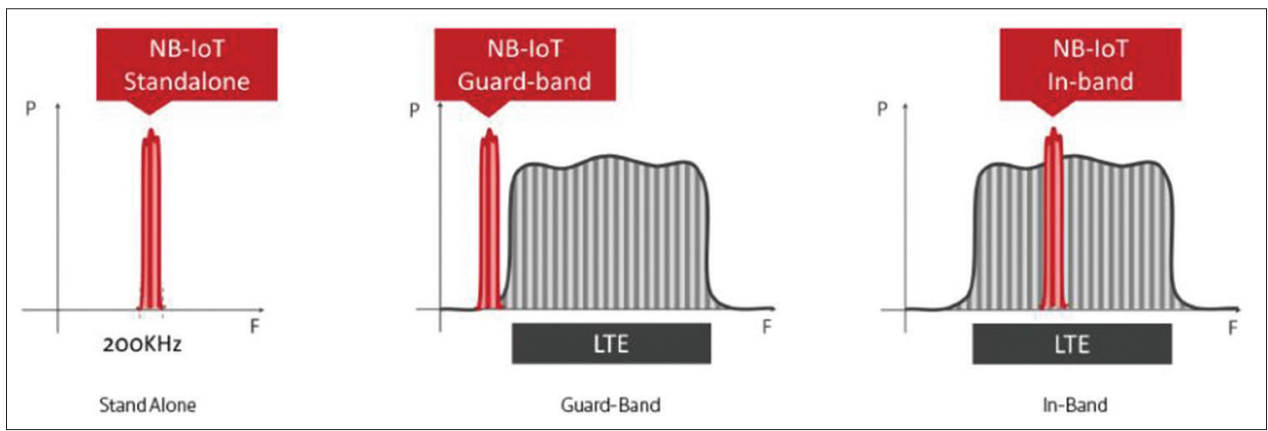

Fig. 3. Three deployments supported by Narrowband Internet of Things.

(FS1), as shown in Fig. 4. Upper link supports FS1 for under carrier spacing of $15 \mathrm{kHz}$. However, for spacing under carrier $3.75 \mathrm{kHz}$, a new type of framework is defined Fig. 5 .

\section{KEY TECHNOLOGY OF NB-IOT}

\subsection{Connection Analysis Theory}

3GPP analyzes several connections that NB-IoT can access it when network supports from terminal periodic reporting service and network command reporting service. It is assumed that services are distributed within a day and NB-IoT can support 52547 connectivity per cell. Indeed, this assumption is too ideal, which almost ignores the business of NB-IoT service. As a result, it is difficult to generalize it in other application scenes. At present, there are few studies in NBIoT business service. However, the research results of LTE-M (machine type communications [MTC]) and enhanced MTC are still valuable to learn. To overcome LTE network access overhead at a time a lot of MTC terminals enter the network at the same time, researchers have focused their analysis on LTE random access channel (RACH) load pressure and additional load control mechanisms. Researches typically coordinate service entering process as a homogeneous/hybrid process with the same distribution. The users retransitions the number of packet in queue head or channel position in a specific time slot as position variables for obtaining a stable graphical plot with the assumption of completing multichannel S-ALOHA static mode performance analysis.. The

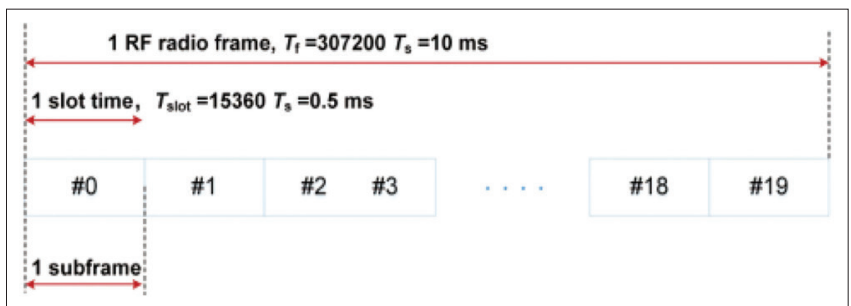

Fig. 4. Narrowband Internet of Things framework structure for spacing under carrier of $15 \mathrm{kHz}$ for upper and lower links [42].

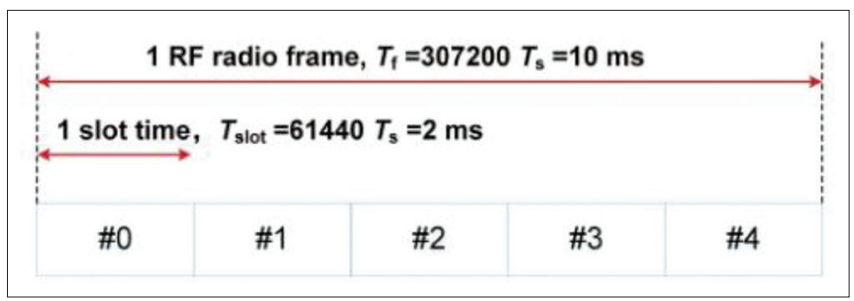

Fig. 5. Narrowband Internet of Things framework structure for spacing under carrier of $3.75 \mathrm{kHz}$ for upper link [42].

graphing plan can be used for LTE RACH optimal design. However, when a lot of MTC terminals enter the network simultaneously, a large number of MTC terminals are sent simultaneously to the network to request a quick meeting in a short time to respond the same incident or monitoring the relevant components. This feature can be hardly described by classical homogeneous/hybrid Poisson process which forms direct application of network performance analysis method 
based on stable state hypotheses. Hence, a transient functional analysis method is essential for multi-channel S-ALOHA of non-Poisson services [24], [25], [26].

\subsection{The Latency Analysis Theory}

Besides the numbers of connecting analysis, 3GPP indicates that there is a need for a theoretical latency model capable of addressing the latency of synchronization, random access, resource allocation, and data transmission to access the upper link. Some of these latencies are concerned with signal detection and service behavior as researchers in the field have concentrated on mean and random-access latency variance and little attention has been paid to other curtail features such as probability density function (PDF) of latency. Researchers such as Rivero-Angeles et al. [26] and Liu et al. [27] have used the Markov process to produce probability generation function from PDF. However, the complex nature of computing has made it difficult for researchers to find a mechanism to lower latency and increase communication probability.

\subsection{Covering Enhancement Mechanism}

Slender band adjustment and sub-GHz arrangement from NB-IoT can upgrade, getting affectability to build inclusion capacity. Besides, 3GPP suggests another advancement component dependent on coverage classes, which is another idea presented for NB-IoT by 3GPP.

\subsection{Very Low Energy Technology}

A major issue with IoT is energy consumption. Researchers have simulated the energy consumption for terminal services within NB-IoT with the aim to identify an area for improvements and the result showed that if the information is transmitted once a day, the life expectancy of a $5 \mathrm{Wh}$ battery could be much prolonged. This leads to the suggestion that an evaluation mechanism for energy efficiency is required to ensure that lower energy consumption for IoT is achieved. Some researches, such as Liu et al. [27] and Balasubramanya et al. [28], on energy consumption in DRX focuses on single terminals between control signaling states and terminal operating mode. However, more work is needed to find a holistic mechanism that is seen as one of the tasks of 3GPP R14.

\subsection{Connectivity between Signaling and Data}

Coupling simulation between data and signaling is another concern in IoT that companies such as Huawei technology have indicated needs to be addressed. This is because in many simulation tools, data and signals are separated and simulation tests are done for each independently. This leads to a result where issues in connecting the two cannot be understood which makes it difficult to simulate real network capacity, for example, when access to MTC terminals are requested [29], [30].

\section{NB-IOT AND DIFFERENT WIRELESS COMMUNICATION TECHNOLOGIES}

LPWA technology is gaining popularity as Io'T services grow rapidly. The technology is used to deliver smart services with low data speed, which can be utilized in IoT intelligent applications. These applications are classified into three groups by Hekwan Wu in the 2016 International Internet Conference in China, as shown in Table 4.

Fig. 6a illustrates the position of (LPWAN) in comparison to other communication technologies in terms of inclusion zone and information transmission rate. This type of technology is most suited to applications that require high bandwidth and short-range transmission speed such as Bluetooth and ZigBee [31], [32], [33].

TABLE 4: Distribution statistics for loT smart connection technology in 2020

\begin{tabular}{|c|c|c|c|}
\hline $\begin{array}{l}\text { Global M2M/loT connection } \\
\text { distribution in } 2020\end{array}$ & Category & Network connection techniques & Fine-grained market opportunity \\
\hline $10 \%$ & $\begin{array}{l}\text { High data rate (>10 Mbps), } \\
\text { e.g., C- CTV, eHealth }\end{array}$ & $\begin{array}{l}\text { 3G: HSPA/EVDO/TDS } \\
\text { 4G: LTE/LTE-A } \\
\text { WiFi } 802.11 \text { technologies }\end{array}$ & $\begin{array}{l}\text { Big profit margin for car navigation/ } \\
\text { entertainment system }\end{array}$ \\
\hline $30 \%$ & $\begin{array}{l}\text { Medium data rate (<1 Mbps), } \\
\text { e.g., POS, smart home, M2M } \\
\text { backhaul }\end{array}$ & $\begin{array}{l}\text { 2G: GPRS/CDMA2KIX } \\
\text { MTC/eMTC }\end{array}$ & $\begin{array}{l}\text { 2G M2M could be replaced by MTC/ } \\
\text { eMTC techniques }\end{array}$ \\
\hline
\end{tabular}

NB-IoT: Narrowband Internet of Things, GPRS: General packet radio services, eMTC: Enhanced machine-type communications 
Fig. $6 \mathrm{~b}$ shows the position of NB-IoT that makes use of both $4 \mathrm{G} / 5 \mathrm{G}$ attributes and low power radio technology and advantages of low-energy consumption remote correspondence advances (e.g., ZigBee innovation) to be specific concentrated transmission and minimal effort.

We have further investigated the technology and compared it with LoRa, which is a type of WAN communication technology, as shown in Table 5.

\section{REQUIREMENTS FOR NB-IOT SECURITY}

Security requirements for NB-Io'T are similar to that of traditional Io $T$ with a number hardware, energy consumption, and network connection mode differences. Traditional IoT normally has a robust computing power with strong internal security design but with high energy consumption [34], [35], [36]. There are IoT technologies equipped with low-power hardware, but in return, it offers a low computing power with high-security risk which may lead to service denial. As a consequence, any security violation, even on a small scale, may leave a negative lasting effect as terminals are simpler and easier for attackers to obtain information. Researchers in Chen et al. [35], Li et al. [36], Mangalvedhe et al. [37], and Koc et al. [38] have analyzed NB-IoT security requirements, which is distributed over three layers, as shown in Fig. 7.

The below explanation introduces the security prerequisites of NB-IoT planning to the 3-layer design comprised perception layer, transition layer, and application layer.

\subsection{Perception Layer}

Perception layer is NB-IoT base layer that shows fundamental and establishment of administration and engineering higher layers. NB-IoT observation layer, for example, regular discernment layer, will, in general, be under latent and dynamic assaults. Uninvolved assault implies trespasser ransacks data with no redress. The fundamental highlights incorporate listening in, rush hour gridlock investigation, etc. As NB-IoT depended on an open remote system, trespassers may discover data about NB-IoT terminals with strategies, for example, information connect theft and traffic properties examination to focus on a progression of resulting assaults.

\subsection{Transition Layer}

Contrasted with the traditional layer in customary IoT, NB-IoT changes complex system organization that implies hand-off entryway gathers data and afterward sends it to the

\section{TABLE 5: Comparison of NB-IoT and LoRa}

\begin{tabular}{|c|c|c|}
\hline Item & NB-IoT & LoRa \\
\hline $\begin{array}{l}\text { Power } \\
\text { consumption }\end{array}$ & Low (10 years battery life) & $\begin{array}{l}\text { Low (10 years } \\
\text { battery life) }\end{array}$ \\
\hline Cost & Low & Lower than NB-IoT \\
\hline Safety & Telecom level security & Slight interference \\
\hline Accuracy rate & High & High \\
\hline Coverage & $<25 \mathrm{~km}$ (resend supported) & $<11 \mathrm{~km}$ \\
\hline Deployment & $\begin{array}{l}\text { Rebuild supported based } \\
\text { on LTE FDD or GSM }\end{array}$ & Inconvenience \\
\hline
\end{tabular}

NB-loT: Narrowband Internet of Things, GSM: Global system for mobile, FDD: Foreign demand draft

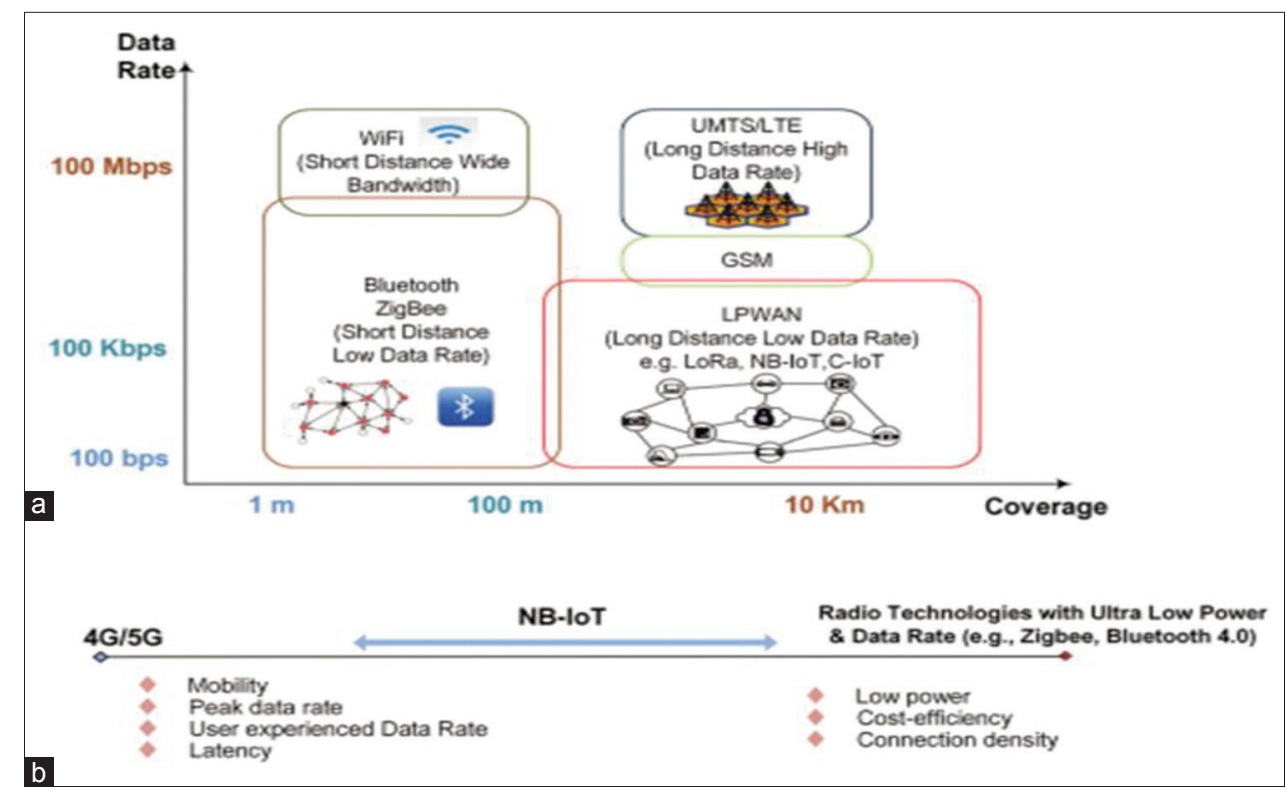

Fig. 6. Correlation between Narrowband Internet of Things (NB-IoT) and different wireless communication technologies (a) comparison of various wireless communication technologies. (b) NB-loT design exchanges. 


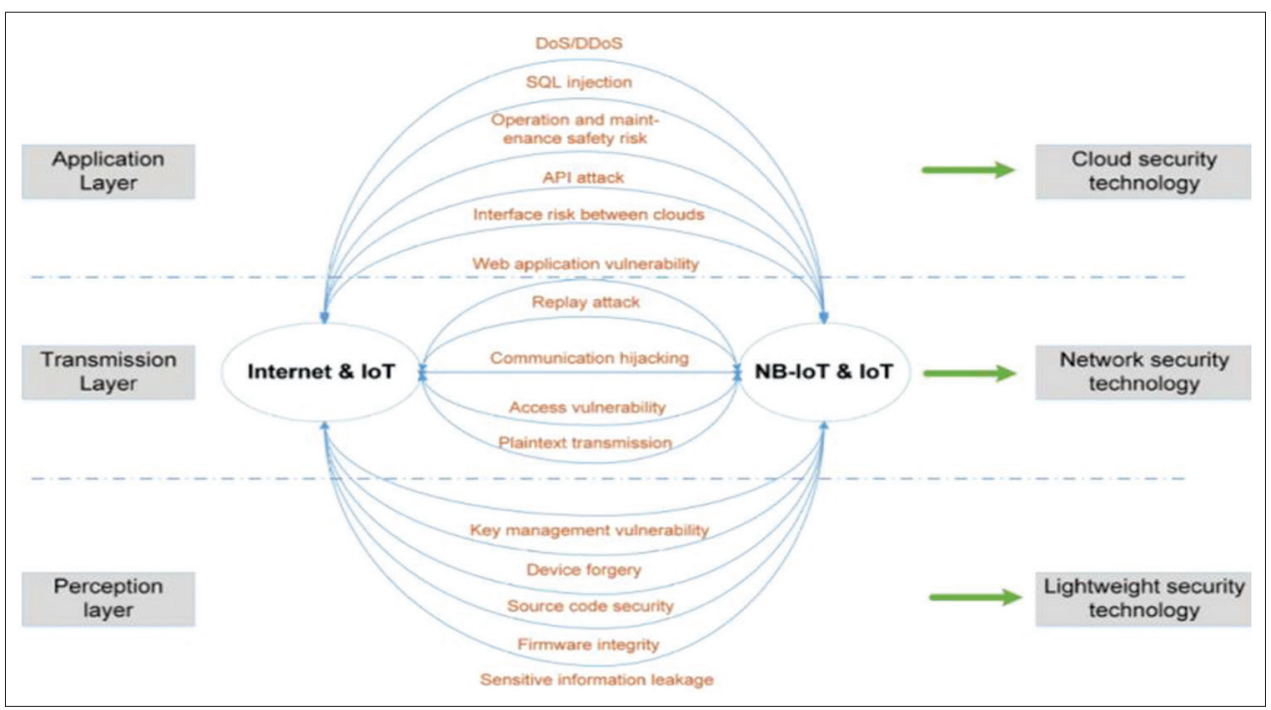

Fig. 7. Similarity between traditional Narrowband Internet of Things (IoT) and loT in terms of security requirements.

base station for sustaining. Subsequently, numerous issues, for example, multi-organizing, significant expense, and battery with a high limit, are illuminated. A system for the entire city can carry simplicity of upkeep and the board with advantages, for example, advantageous tending to and establishment through detachment from property administration.

\subsection{Application Layer}

The purpose of the NB-Io'T application layer is to store, analyze, and manage data efficiently. After the perception and transfer layer, a large amount of data converges in the application layer. Then, vast resources are formed to provide data support from different applications. Compared to the traditional IoT application layer, the NB-IoT application layer carries more data [37], [38], [39], [40].

\section{CONCLUSION}

In this paper, we reviewed the basic properties, benefits, and background and the latest scientific findings of NBIoT. The general background of the IoT was introduced. The benefits, features, basic theory, and NB-IoT key technologies such as connection analysis, latency analysis, and coverage enhancement analysis were provided. Subsequently, we focused on differences between NB-IoT and different types of communication technologies. Finally, we made a comparison between NB-IoT and other wireless communication technologies and we examine NB-IoT security requirements from three levels; perception layer, transition layer, and application layer. There are many future research paths for this study. We continue to investigate a visible network model that can visually reflect the status of NB-IoT network operation. Such a model should complete each of the operational modules and do link-level open type simulation and NB-IoT confirmation form pellet.

\section{REFERENCES}

[1]. P. Reininger. "3GPP Standards for the Internet-of-Things". Technologies Report, Huawei, Shenzhen, China, 2016.

[2]. "Feasibility Study on New Services and Markets Technology Enablers for Massive Internet of Things". Document TR 22.861, 3GPP, 2016.

[3]. M. Chen, Y. Qian, Y. Hao, Y. Li and J. Song. "Data-driven computing and caching in 5G networks: Architecture and delay analysis". IEEE Wireless Communications, vol. 25, no. 1, pp. 70-75, 2018.

[4]. 3GPP. "Standardization of NB-IoT Completed", 2016. Available from: http://www.3gpp.org/news-events/3gpp-news/1785-nb_loT complete. [Last accessed on 2018 Oct 01].

[5]. A. Rico-Alvarino, M. Vajapeyam, H. Xu, X. Wang, Y. Blankenship, J. Bergman, T. Tirronen and E. Yavuz. "An overview of 3GPP enhancements on machine to machine communications". IEEE Communications Magazine, vol. 54, no. 6, pp. 14-21, 2016.

[6]. Ericsson. "Cellular Networks for Massive IoT'. Technologies Report, Ericsson, Stockholm, Sweden, 2016.

[7]. Y. L. Zou, X. J. Ding and Q. Q. Wang. "Key technologies and application prospect for NB-IoT". ZTE Technology Journal, vol. 23, no. 1, pp. 43-46, 2017.

[8]. A. Laya, L. Alonso and J. Alonso-Zarate. "Is the random access channel of LTE and LTE-A suitable for M2M communications? A survey of alternatives". IEEE Communications Surveys and Tutorials, vol. 16, no. 1, pp. 4-16, 2014.

[9]. RloT. "Low Power Networks Hold the Key to Internet of Things". Technologies Report, Berlin, Germany, 2015.

[10]. X. Ge, X. Huang, Y. Wang, M. Chen, Q. Li, T. Han and C. X. Wang. "Energy-efficiency optimization for MIMO-OFDM mobile multimedia 
communication systems with QoS constraints". IEEE Transactions on Vehicular Technology, vol. 63, no. 5, pp. 2127-2138, 2014.

[11]. P. Osti, P. Lassila, S. Aalto, A. Larmo and T. Tirronen. "Analysis of PDCCH performance for M2M traffic in LTE". IEEE Transactions on Vehicular Technology, vol. 63, no. 9, pp. 4357-4371, 2014.

[12]. G. C. Madueno, Č. Stefanović and P. "Popovski. Reengineering GSM/GPRS Towards a Dedicated Network for Massive Smart Metering". In: IEEE International Conference on Smart Grid Communications (SmartGridComm), pp. 338-343, 2014.

[13]. W. Liu, J. Dong, N. Liu, Y. L. Chen, Y. B. Han and Y. B. Ren. "NB-IoT key Technology and Design Simulation Method". Telecommunications Science, China, pp. 144-148, 2016.

[14]. M. Centenaro and L. Vangelista. "A Study on M2M Traffic and Its Impact on Cellular Networks". In: 2015 IEEE $2^{\text {nd }}$ World Forum on Internet of Things (WF-IoT), pp. 154-159, 2015.

[15]. G. Y. Lin, S. R. Chang and H. Y. Wei. "Estimation and Adaptation for Bursty LTE Random Access", vol. 65. In: IEEE Transactions on Vehicular Technology, pp. 2560-2577, 2016.

[16]. Q. Xiaocong and M. Mingxin. "NB-loT standardization technical characteristics and industrial development". Information Research, vol. 5, pp. 523-526, 2016.

[17]. M. T. Islam, M. T. Abd-elhamid and S. Akl. "A Survey of Access Management Techniques in Machine Type Communications". Vol. 52. IEEE Communications Magazine, Piscataway, pp. 74-81, 2014.

[18]. G. H. Dai and J. H. Yu. "Research on NB-lo T background, standard development, characteristics and the service". Mobile Communications, vol. 40, no. 7, pp. 31-36, 2016.

[19]. M. A. Khan and K. Salah. "loT security: Review, blockchain solutions, and open challenges". Future Generation Computer Systems, vol. 82, pp. 395-411, 2018.

[20]. V. Kharchenko, M. Kolisnyk, I. Piskachova and N. Bardis. "Reliability and Security Issues for loT-based Smart Business Center: Architecture and Markov Model". In: 2016 Third International Conference on Mathematics and Computers in Sciences and in Industry (MCSI), pp. 313-318, 2016.

[21]. J. J. Nielsen, D. M. Kim, G. C. Madueno, N. K. Pratas and P. Popovski. "A Tractable Model of the LTE Access Reservation Procedure for Machine-type Communications". In: 2015 IEEE Global Communications Conference (GLOBECOM). pp. 1-6, 2015.

[22]. C. H. Wei, R. G. Cheng and S. L. Tsao. "Performance analysis of group paging for machine-type communications in LTE networks". IEEE Transactions on Vehicular Technology, vol. 62, no. 7, pp. 3371-3382, 2013.

[23]. M. Koseoglu. "Lower bounds on the LTE-A average random access delay under massive M2M arrivals". IEEE Transactions on Communications, vol. 64, no. 5, pp. 2104-2115, 2016.

[24]. S. Persia and L. Rea. "Next generation M2M cellular networks: LTEMTC and NB-loT capacity analysis for smart grids applications". In: 2016 AEIT International Annual Conference (AEIT), pp. 1-6, 2016.

[25]. T. M. Lin, C. H. Lee, J. P. Cheng and W. T. Chen. "PRADA: Prioritized random access with dynamic access barring for MTC in 3GPP LTE-A networks". IEEE Transactions on Vehicular Technology, vol. 63, no. 5, pp. 2467-2472, 2014.

[26]. M. E. Rivero-Angeles, D. Lara-Rodriguez F. A. Cruz-Perez. "Gaussian approximations for the probability mass function of the access delay for different backoff policies in S-ALOHA". IEEE Communications Letters, vol. 10, no. 10, pp. 731-733, 2006.

[27]. J. Liu, J. Wan, B. Zeng, Q. Wang, H. Song and M. Qiu. "A scalable and quick-response software defined vehicular network assisted by mobile edge computing". IEEE Communications Magazine, vol. 55, no. 7, pp. 94-100, 2017.

[28]. N. M. Balasubramanya, L. Lampe, G. Vos and S. Bennett. "DRX with quick sleeping: A novel mechanism for energy-efficient loT using LTE/LTE-A". IEEE Internet of Things Journal, vol. 3, no. 3, pp. 398-407, 2016.

[29]. K. Lin, D. Wang, F. Xia, H. Ge. "Device clustering algorithm based on multimodal data correlation in cognitive internet of things". IEEE Internet of Things Journal, vol. 5, no. 4, pp. 2263-2271, 2018.

[30]. G. Naddafzadeh-Shirazi, L. Lampe, G. Vos and S. Bennett. "Coverage enhancement techniques for machine-to-machine communications over LTE". IEEE Communications Magazine, vol. 53, no. 7, pp. 192-200, 2015.

[31]. F. Xu, Y. Li, H. Wang, P. Zhang and D. Jin. "Understanding mobile traffic patterns of large scale cellular towers in urban environment". IEEE/ACM Transactions on Networking, vol. 25, no. 2, pp. 11471161, 2017.

[32]. Y. Li, F. Zheng, M. Chen and D. Jin. "A unified control and optimization framework for dynamical service chaining in softwaredefined NFV system". IEEE Wireless Communications, vol. 22, no. 6, pp. 15-23, 2015.

[33]. X. Ge, J. Yang, H. Gharavi and Y. Sun. "Energy efficiency challenges of $5 \mathrm{G}$ small cell networks". IEEE Communications Magazine, vol. 55, no. 5, pp. 184-191, 2017.

[34]. X. Yang, X. Wang, Y. Wu, L. P. Qian, W. Lu and H. Zhou. "Small-cell assisted secure traffic offloading for narrow band internet of thing (NB-IoT) systems". IEEE Internet of Things Journal, vol. 5, no. 3, pp. 1516-1526, 2018.

[35]. L. Chen, S. Thombre, K. Järvinen, E. S. Lohan, A. Alén-Savikko, H. Leppäkoski, M. Z. Bhuiyan, S. Bu-Pasha, G. N. Ferrara, S. Honkala and J. Lindqvist. "Robustness, security and privacy in location-based services for future IoT: A survey". IEEE Access, vol. 5, pp. 8956-8977, 2017.

[36]. Y. Li, X. Cheng, Y. Cao, D. Wang and L. Yang. "Smart choice for the smart grid: Narrow band Internet of Things (NB-IOT)". IEEE Internet of Things Journal, vol. 5, no. 3, pp. 1505-1515, 2018.

[37]. N. Mangalvedhe, R. Ratasuk and A. Ghosh. "NB-loT deployment Study for Low Power Wide Area Cellular IoT". In: 2016 IEEE $27^{\text {th }}$ Annual International Symposium on Personal, Indoor, and Mobile Radio Communications (PIMRC), pp. 1-6, 2016.

[38]. A. T. Koc, S. C. Jha, R. Vannithamby and M. Torlak. "Device power saving and latency optimization in LTE-A networks through DRX configuration". IEEE Transactions on Wireless Communications, Vol. 13, no. 5, pp. 2614-2625, 2014.

[39]. R. Cheng, A. Deng and F. Meng. "Study of NB-IoT Planning Objectives and Planning Roles". China Mobile Group Design Inst. Co., Technical Reports Telecommunications Science, 2016.

[40]. Y. Hou, and J. Wang. "LS-SVM's No-reference Video Quality Assessment Model Under the Internet of Things". In: 2017 IEEE Smart World, Ubiquitous Intelligence and Computing, Advanced and Trusted Computed, Scalable Computing and Communications, Cloud and Big Data Computing, Internet of People and Smart City Innovation (Smart World/SCALCOM/UIC/ATC/CBDCom/IOP/SCI), pp. 1-8, 2017.

[41]. R. Aleksandar, P. Ivan, P. Ivan, B. Đorđe, S. Vlado and R. Miriam. "Key Aspects of Narrow Band loT Communication Technology Driving Future IoT Applications". Conference: In: 2017 IEEE Telecommunication Forum (TELFOR), 2017.

[42]. C. Min, M. Yiming, H. Yixue, A. K. HWANG. "Narrow band internet of things". IEEE Access, vol. 5, pp. 20557-20577, 2017. 